\title{
High Performance Liquid Chromatography Method for the Estimation of Water Soluble Vitamin in Five Wild Edible Fruits Consumed by the Tribal People of North-Eastern Region in India
}

\author{
Tapan Seal $^{*}$ and Kausik Chaudhuri
}

\author{
Plant Chemistry Department, Botanical Survey of India, Acharya Jagadish Chandra \\ Bose Indian Botanic Garden, Shibpur, Howrah-711103, West Bengal, India \\ *Corresponding author
}

\begin{tabular}{|c|c|}
\hline & A B S T R A C T \\
\hline & \multirow{7}{*}{$\begin{array}{l}\text { A reversed-phase high-performance liquid chromatographic method has been developed } \\
\text { for the simultaneous quantitation of water-soluble vitamins like ascorbic acid (C), thiamine } \\
\text { (B1), riboflavin (B2), niacin (B3), pantothenic acid (B5), pyridoxine (B6) and folic acid } \\
\text { (B9) in five potent wild edible fruits named Morus indica, Meynalaxi flora, Solanum gilo, } \\
\text { Solanum kurzii and Viburnum foetidum, consumed by the tribal people of North-eastern } \\
\text { region in India. The experimental results showed that for different fruits, the vitamin C } \\
\text { content ranged between } 6.23 \pm 0.04 \text { and } 51.59 \pm 0.40 \mathrm{mg} / 100 \mathrm{~g} \text { dry plant materials. The B1 } \\
\text { content was determined high in } M \text {. laxiflora }(1.10 \pm 0.010 \mathrm{mg} / 100 \mathrm{~g} \text { and minimum in the } \\
\text { fruits of } S \text {. kurzii. A significant amount of B3 }(15.04 \pm 0.08 \mathrm{mg} / 100 \mathrm{gm}) \text { and good amount } \\
\text { of B2 (1.44 } \pm 0.006 \mathrm{mg} / 100 \mathrm{gm}) \text { and B9 }(0.95 \pm 0.0 \mathrm{mg} / 100 \mathrm{gm}) \text { were detected in } M \text {. } \\
\text { laxiflora. The results of investigation showed that these fruits are rich sources of vitamins } \\
\text { that can contribute immensely to nutrition and food security. The high percentage of } \\
\text { recovery and low limit of detection confirm the suitability of the method for simultaneous } \\
\text { quantification of vitamins in these five fruits. }\end{array}$} \\
\hline Keywords & \\
\hline & \\
\hline vitamins, B group & \\
\hline C, HPLC Analysis. & \\
\hline Article Info & \\
\hline $\begin{array}{l}\text { Accepted: } \\
\text { 23 September } 2017 \\
\text { Available Online: } \\
10 \text { October } 2017\end{array}$ & \\
\hline
\end{tabular}

\section{Introduction}

Vitamins are essential substances which are required in small amounts in the body on a regular basis for normal health and various physiological functions in the human body. They are widely distributed in natural food sources and can be easily introduced into the diets to satisfy daily needs. Though vitamins are a group of organic compounds that have different structural and chemical properties, they can be conveniently categorized into two groups based on their solubility: fat-soluble vitamins and water-soluble vitamins. The former includes lipid soluble vitamins $\mathrm{A}, \mathrm{D}$, $\mathrm{E}$, and $\mathrm{K}$ and other carotenoids, the latter is composed of water soluble vitamin $\mathrm{C}$ and eight B-vitamins, namely thiamine (B1), riboflavin (B2), niacin (B3), pyridoxine (B6), pantothenic acid (B5), biotin (B7), folate (B9) and cyanocobalamin (B12) (Harris 2003).

Vitamins often occur in food at relatively low levels and susceptible to degradation by exposure to light, air, heat and high $\mathrm{pH}$. Due to the varied chemical structures and properties of vitamin, it is very difficult to develop a single universal method for their simultaneous quantification. Moreover, each vitamin can occur in different forms that 
possess the same biological activity upon consumption. Different instrumental methods have been developed for the determination of vitamin $\mathrm{C}$ and $\mathrm{B}$-group vitamins, including spectrophotometry, titration, highperformance liquid chromatography (HPLC), capillary electrophoresis (CE), highperformance thin layer chromatography (HPTLC). Several biological assays have been also described for the determination of water-soluble vitamins in various conditions. The most widely used methods for the determination of ascorbic acid together with B-group vitamins are reversed-phase HPLC coupled with diode array detector, using a C18 column and aqueous-organic mobile phases, in acidic media (Jin et al., 2012).

Plant-derived vitamins are of great interest because of their impact on human health. They are essential for metabolism because of their redox chemistry and role as enzymatic cofactors, not only in animals but also in plants. Several vitamins have strong antioxidant potential, including both watersoluble (vitamins B and C) and lipid-soluble (vitamins $\mathrm{A}, \mathrm{E}$ and $\mathrm{K}$ ) compounds.

Plants rich in fruits, vegetables, whole grains, and legumes, provide an abundance of vitamins and minerals to meet one's nutritional needs. The therapeutic potential of the vegetables is largely dependent on the presence of vital vitamins as well as micronutrients. Even though vitamin is required a small amount per day in health, it plays a vital role in our health. The consumption of leafy vegetables and fruits rich in vitamins, are reported to reduce the risk of attack of various acute and chronic diseases (Hasan et al., 2013)

The wild plants have been a main source of food and medicine for tribal people. These plants have rich nutrition and medicinal values. Regular consumption of vegetables is also recommended for better health and management of chronic diseases. The nutritive value, antioxidant properties of the fruits of wild edible plants like Morus indica, Meynalaxi flora, Solanum gilo, Solanum kurzii and Viburnum foetidum consumed by the tribal people of North-eastern region in India, has already been studied in our laboratory. The quantification of phenolic acids and flavonoids by High performance liquid chromatography (HPLC) has already been carried out with these plants.

Therefore, these wild edible plants have nutritional potential and are worthy of exploitation as a dietary resource due to the presence of sufficient amount of protein, carbohydrate, fat and minerals. The antioxidant properties and the presence of phenolic acids and flavonoids in these wild edible plants in varying amounts have been enriched the nutraceutical properties of these plants (Seal 2011a; Seal 2011b, Seal 2011c; Seal et al., 2016a; Seal et al., 2016b; Seal and Chaudhuri 2016; Seal et al., 2016c).

This study focused on a simple, gradient and stability-indicating HPLC method for the rapid determination of water soluble vitamins like, thiamine (B1), niacin (B3), pyridoxine (B6), ascorbic acid (C), pantothenic acid (B5), riboflavin (B2) and folic acid (B9) in five wild edible fruits collected from Northeastern region in India and all the vitamins were simultaneously analyzed in a single chromatographic run.

\section{Materials and Methods}

\section{Plant material}

The fresh wild edible plants named M.indica, M.laxiflora, S.gilo, S.kurzii and V.foetidum were collected from North-eastern region in India. Plant species were authenticated and a voucher specimen was kept at the Plant 
Chemistry Department, Botanical Survey of India under the Registry No. BSITS 26, BSITS 11, BSITS 8, BSITS 9 and BSITS 2 for future reference. The plant parts were taken in our laboratory at refrigerated temperature using cold packs. The refrigerated plant samples were stored at $15^{\circ} \mathrm{Cand}$ then processed within four days of collection.

\section{Chemicals}

The standards chemicals like ascorbic acid (C), thiamine (B1), riboflavin (B2), niacin (B3), pantothenic acid (B5), pyridoxine (B6) and folic acid (B9) were purchased from Sigma Chemical Co. (St. Louis, MO, USA) and the HPLC-grade solvents such asacetonitrile, methanol, water sodium dihydrogen phosphate and trifluoroacetic acid (TFA) were purchased from Merck (Germany).

\section{HPLC equipment}

HPLC analyses were performed with Dionex Ultimate 3000 liquid chromatograph (Germany) with four solvent delivery system quaternary pump (LPG 3400 SD) including a diode array detector (DAD 3000) with $5 \mathrm{~cm}$ flow cell, a manual sample injection valve equipped with a $20 \mu$ l loop and Chromeleon 6.8 system manager as data processor. The separation was achieved by a reversed-phase Acclaim ${ }^{\mathrm{TM}} 120 \mathrm{C} 18$ column $(5 \mu \mathrm{m}$ particle size, i.d. 4.6 × $250 \mathrm{~mm}$ ).

\section{Preparation of standard solutions}

The stock standard solutions of vitamin $\mathrm{C}$, B1, B3, B5 and B6 and were prepared by dissolving $25 \mathrm{mg}$ of the each standard in one $\mathrm{ml} 0.1 \mathrm{M}$ hydrochloric acid in $25 \mathrm{ml}$ standard volumetric flask and topped up to mark with double distilled water. For preparation of standard stock solutions of vitamin B9 and B2,25 $\mathrm{mg}$ of the each standard were dissolved in one $\mathrm{ml} 0.1 \mathrm{M}$ sodium hydroxidein $25 \mathrm{ml}$ standard volumetric flask and made up to mark with double distilled water. The standard solution was stored in amber-glass bottles in the refrigerator at $4^{0} \mathrm{C}$. The working standards were prepared from the stock standard solutions by mixing $100 \mu \mathrm{l}$ mixed vitamins standard (vitaminB9, B5 and B2),800 $\mu$ lphosphate buffer (1 M, pH 5.5) and $100 \mu 1$ mixed vitamins standard (vitamin $\mathrm{C}$, B1, B6 and B3) which represent $100 \mu \mathrm{g} / \mathrm{ml}$ mixed working standards. The working standard solutions of concentrations 20, 40, 60 and $80 \mu \mathrm{g} / \mathrm{ml}$ were prepared accordingly.

\section{Preparation of sample solution}

Plant materials were cleaned and the inedible portions were removed. The edible parts were rinsed thoroughly with tap water and then with distilled water. The washed plant materials were dried with clean cloth, were cut into very small pieces, frozen in liquid nitrogen, freeze-dried and kept at $-20{ }^{\circ} \mathrm{C}$ until analysis.

One gm of each freeze-dried plant materials were soaked in $10 \mathrm{ml}$ water. Then $1 \mathrm{ml} 0.1 \mathrm{M}$ $\mathrm{NaOH}$ and $10 \mathrm{ml}$ phosphate buffer $(1 \mathrm{M}, \mathrm{pH}$ 5.5) were added to it and kept in dark for 24 hours. The solution was first filtered through a Whatman No. 1 filter paper and the resulting filtrate was taken in a $25 \mathrm{ml}$ volumetric flask and solution was topped up to the mark with HPLC grade water. The sample solution was filtered through $0.45 \mu \mathrm{m}$ membrane filter before injection into HPLC system the stock solutions of sample were kept in a refrigerator for further use (Ciulua et al., 2011)

\section{Chromatographic analysis of water soluble vitamins}

The chromatographic analysis was carried out following the method as described by Marco Ciulua (Ciulua et al., 2011) with minor 
modification. The mobile phase contains acetonitrile (Solvent A) and aqueous trifluoro acetic acid (TFA, $0.01 \% \mathrm{v} / \mathrm{v}$ ) (Solvent B), the column was thermostatically controlled at $22^{0}$ $\mathrm{C}$ and the injection volume was kept at $20 \mu \mathrm{l}$. A gradient elution was performed by varying the proportion of solvent A to solvent B. The gradient elusion was $1 \% \mathrm{~A}$ and $99 \% \mathrm{~B}$ with flow rate $0.5 \mathrm{ml} / \mathrm{min}$ in $5 \mathrm{~min}$, from $1 \%$ to $25 \%$ A with flow rate $0.5 \mathrm{ml} / \mathrm{min}$ for $16 \mathrm{~min}$, $45 \% \mathrm{~A}$, with flow rate $0.5 \mathrm{ml} / \mathrm{min}$ for $8 \mathrm{~min}$. from 45 to $1 \%$ A with flow rate $0.5 \mathrm{ml} / \mathrm{min}$ in 5 min. The mobile phase composition back to initial condition (solvent A: solvent B: 1: 99) in $34 \mathrm{~min}$ and allowed to run for another 1 min, before the injection of another sample. Total analysis time per sample was $35 \mathrm{~min}$.

The various concentrations of $(20,40.60,80$ and $100 \mu \mathrm{g} / \mathrm{ml}$ ) vitamin working standards were injected into the HPLC column separately and the retention times were noted and used to identify the vitamins in the sample.

HPLC Chromatograms of all vitamins were detected using a photo diode array UV detector at four different wavelengths (210, 245, 275 and $290 \mathrm{~nm}$ ) according to absorption maxima of analysed compounds. Each compound in the plant extracts were identified by its retention time and by spiking with standards under the same conditions.

The quantification of the sample was done by the measurement of the integrated peak area and the content was calculated using the calibration curve by plotting peak area against concentration of the respective standard sample. The data were reported as means \pm standard error means of three independent analyses.

\section{Validation of the method}

According to the USP and ICH guidelines (ICH-Q2A 1995; ICH-Q2B 1996) various parameters were studied to validate the reproducibility of the method viz. the effectiveness, the linearity, the limit of detection (LOD), the limit of quantitation (LOQ), the precision and the accuracy.

\section{Effectiveness}

The effectiveness of the HPLC method was detected with the standard solutions of water soluble vitamins. Generally, methanol of diverse composition is used as eluent but solvents like acetonitrile, acetic acid, formic acid are also reported in the literature. In this study, different proportion of acetonitrile and $0.01 \% \mathrm{v} / \mathrm{v}$ TFA was used to achieve the best resolution.

\section{Linearity}

To ascertain the linearity, the stock solution of the standard $(1 \mathrm{mg} / \mathrm{ml})$ was diluted to five different concentrations $(20,40,60,80$ and $100 \mu \mathrm{g} / \mathrm{ml}$ ) which were fed individually in triplicate to the HPLC system and the calibration curve so obtained by plotting peak area versus concentration for each sample where the square of the correlation coefficient $\mathrm{R} 2>0.99$ is indicative of the measure of linearity.

\section{Accuracy}

The accuracy of the method was determined by application of the standard addition method. The extracts of wild edible plants were spiked with two known concentration of calibration solutions $(20 \mu \mathrm{g} / \mathrm{ml}$ and $40 \mu \mathrm{g} / \mathrm{ml})$. The amounts of water soluble vitamins present in the investigated plants were previously determined. For each standard compound, the percentage of recovery was calculated as follows

Recovery $(\%)=$ (amount found - amount contained)/amount added $\times 100$ 
The high recovery rate in the range of $98-99$ $\%$ for the samples is indicative of efficacy and consistency

\section{Limit of detection (LOD) and limit of quantitation (LOQ)}

Limit of detection and limit of quantitation were calculated using the following formula $\mathrm{LOD}=3.3(\sigma) / S$ and $\mathrm{LOQ}=10(\sigma) / S$, where $(\sigma)=$ standard deviation of response (peak area) and $S=$ slope of the calibration curve. The precision refers to the degree of proximity of the results expressible as \% relative standard deviation (RSD) of the retention time and the peak area. The repeatability of the retention time and peak areas $(\mathrm{Pa})$ were checked by injecting the mixed standard solutions at two concentration levels $(40 \mu \mathrm{g} / \mathrm{ml}$ and $60 \mu \mathrm{g} / \mathrm{ml})$ into the HPLC system. The RSD of retention time and peak areas were calculated for five replicate determinations.

\section{Statistical analysis}

The significant and non-significant variations within water soluble vitamin contents and the five wild edible plants were analyzed using one-way analysis of variance (ANOVAs). Values are means of five replicates from two experiments, and the presented mean values were separated using Duncan's Multiple Range Test (DMRT) at $\mathrm{p}<0.05$.

\section{Results and Discussion}

\section{Chromatographic method}

A typical HPLC chromatogram of the all standard vitamin mixture recorded at $210 \mathrm{~nm}$ is presented in figure 1. As shown in the chromatogram, all investigated compounds had responses at $245 \mathrm{~nm}$, where they were successfully separated. The constituents under investigation were also identified by the recorded absorption spectra, which were comparable both for plant extracts and standard substances. The regression coefficient together with LOD and LOQ values, are shown in table 1 . The high value of $\mathrm{R}^{2}>0.9906$ in the range of analyzed concentrations at 210, 245 and $275 \mathrm{~nm}$ is indicative of responsive linearity.

\section{Identification and quantification of water soluble vitamins in the wild edible fruits}

The HPLC method was successfully performed for the estimation of water soluble vitamin e.g ascorbic acid (C), thiamine (B1), riboflavin (B2), niacin (B3), pantothenic acid (B5), pyridoxine (B6) and folic acid (B9). The quantity of all vitamins of all plant materials has been expressed as $\mathrm{mg} / 100 \mathrm{gm}$ dry plant material and data presented in table 2 .

The HPLC chromatogram of the fruits of $M$. indica showed the presence of vitamin $\mathrm{C}, \mathrm{B} 1$, B3, B6 and B9 amounting 13.43 \pm 0.04 , $0.092 \pm 0.003, \quad 4.43 \pm 0.03, \quad 0.17 \pm 0.002$ and $0.045 \pm 0.001 \mathrm{mg} / 100 \mathrm{gm}$ respectively as illustrated in figure 2 .

The HPLC study of the fruits of M. laxiflora (Fig. 3) showed the presence of vitamin $\mathrm{C}$ $(29.29 \pm 0.032 \mathrm{mg} / 100 \mathrm{gm})$, B1 $(1.10 \pm 0.010$ $\mathrm{mg} / 100 \mathrm{gm}), \mathrm{B} 2(1.44 \pm 0.006 \mathrm{mg} / 100 \mathrm{gm}), \mathrm{B} 5$ $(0.16 \pm 0.002 \mathrm{mg} / 100 \mathrm{gm})$, B6 $(0.44 \pm 0.004$ $\mathrm{mg} / 100$ gm), B9 $(0.95 \pm 0.02 \mathrm{mg} / 100 \mathrm{gm})$ along with very good amount of B3 $(15.04 \pm 0.08 \mathrm{mg} / 100 \mathrm{gm})$.

The fruits of $S$. gilo revealed the presence of vitamin C $(51.59 \pm 0.40 \mathrm{mg} / 100 \mathrm{gm}), \quad$ B1 $(0.870 \pm 0.007 \mathrm{mg} / 100 \mathrm{gm}), \quad$ B2 $\quad(0.72 \pm 0.02$ $\mathrm{mg} / 100 \mathrm{gm}), \mathrm{B} 3(0.43 \pm 0.008 \mathrm{mg} / 100 \mathrm{gm}), \mathrm{B} 6$ $(0.64 \pm 0.01 \mathrm{mg} / 100 \mathrm{gm})$ and $\mathrm{B} 9(0.10 \pm 0.004$ $\mathrm{mg} / 100 \mathrm{gm}$ ) whereas the fruits of $S$. kurzii contained the same vitamins $(\mathrm{C}, \mathrm{B} 1, \mathrm{~B} 2, \mathrm{~B} 3$, B6 and B9) amounting 6.23 \pm 0.04 , $0.05 \pm 0.004, \quad 0.055 \pm 0.007, \quad 0.28 \pm 0.008$, 
$0.015 \pm 0.001, \quad 0.03 \pm 0.001 \quad \mathrm{mg} / 100 \mathrm{gm}$ respectively as presented in figures 4 and 5 .

The fruits of $V$. foetidum were found to contain vitamin $\mathrm{C}(12.18 \pm 0.06 \mathrm{mg} / 100 \mathrm{gm})$, B2 $(0.25 \pm 0.007 \mathrm{mg} / 100 \mathrm{gm}), \mathrm{B} 3(0.13 \pm 0.003$ $\mathrm{mg} / 100 \mathrm{gm})$, B5 (0.16 $\pm 0.004 \mathrm{mg} / 100 \mathrm{gm}), \mathrm{B} 6$ $(0.30 \pm 0.006 \mathrm{mg} / 100 \mathrm{gm})$ and $\mathrm{B} 9(0.51 \pm 0.004$ $\mathrm{mg} / 100 \mathrm{gm})$ as described in figure 6 .

\section{Chromatographic method}

The quantitative analysis of water soluble vitamins was carried out using a photo diode array UV detector at four different wavelengths $(210,245,275$ and $290 \mathrm{~nm})$. The detection of vitamin $\mathrm{C}, \mathrm{B} 1$ and $\mathrm{B} 3$ were carried out at wavelength $245 \mathrm{~nm}$, vitamin B2, B6 and B9 were carried out at $275 \mathrm{~nm}$.

The detection wavelength was set at $210 \mathrm{~nm}$ for vitamin B5 as it showed absorption at 209 $\mathrm{nm}$. The chromatographic separation was performed at a flow rate of $0.5 \mathrm{ml} / \mathrm{min}$. The method proposed was rapid and all analytes were completely eluted within $30 \mathrm{~min}$ and the whole chromatographic run was completed in $35 \mathrm{~min}$. The solvent system (acetonitrile and aqueous trifluoro acetic acid (TFA, $0.01 \%$ $\mathrm{v} / \mathrm{v}$ ) was used for the analysis and produced a sharp peak of the studied vitamins.

The repeatability of the retention time for all the standard samples and the relative standard deviation for the peak areas of two standards viz., $40 \mu \mathrm{g} / \mathrm{ml}$ and $60 \mu \mathrm{g} / \mathrm{ml}$ was found to be below one percent. The significantly high rate of recovery $(98.15-99.20 \%)$ of the standard vitamins worth's mention.

It follows that the method under consideration is characterized by precision, accuracy, meticulousness and can be used for the qualitative as also quantitative estimation of water soluble vitamins in the five wild edible plants under investigation.
The aim of this study was to develop simple, gradient, and stability-indicating HPLC method for the determination of Vitamin $\mathrm{C}$, B1, B2, B3, B5, B6 and B9 in five wild edible fruits. Vitamin $C$ is extremely unstable in basic and neutral solutions, but relatively stable in acidic solutions, therefore phosphate buffer ( $\mathrm{pH}$ 5.5) was used as a diluting solution for vitamin C, B1, B3, B5 and B6. Both the vitamins (B2 and B9) were found slightly soluble in water and acidic aqueous solutions, but soluble in basic aqueous solutions. So the stock solutions of vitamin B2 and B9 were dissolved in $0.1 \mathrm{M} \mathrm{NaOH}$ solution and all working standard vitamins were diluted with phosphate buffer ( $\mathrm{pH}$ 5.5) solution

\section{Identification and quantification of water soluble vitamins in the wild edible fruits}

Vitamin $\mathrm{C}$ is the most important vitamin in fruits and vegetables. It is well-known for its antioxidant properties and it helps the body in inhibiting from viral infection, bacterial infections and toxicity. It is required for the prevention of scurvy and maintenance of healthy skin, gums and blood vessels and the deficiency of this vitamin causes bruising, bleeding, dry skin and depression (Olson 1999).

The experimental result showed that, the amount of vitamin $\mathrm{C}$ (ascorbic acid) in five wild edible fruits ranged from $6.23 \pm 0.04$ to $51.59 \pm 0.40 \mathrm{mg} / 100 \mathrm{gm}$. The quantity of vitamin $\mathrm{C}$ was found highest in the fruits of $S$. gilo $(51.59 \pm 0.40 \mathrm{mg} / 100 \mathrm{gm})$. The fruits of $M$. laxiflora contained the second highest amount of vitamin C $(29.29 \pm 0.32 \mathrm{mg} / 100 \mathrm{gm})$ and appreciable amount were detected in $M$. indica and in $V$. foetidum The vitamin $C$ content in these wild edible fruits are very much comparable with some common fruits and vegetables like Momordica charantia (88.58 $\quad 3.46 \mathrm{mg} / 100 \mathrm{gm}), \quad$ Solanum melongena $(44.33 \pm 4.56 \mathrm{mg} / 100 \mathrm{gm})$, 
Vitisvinifera (23.55 $0.95 \mathrm{mg} / 100 \mathrm{gm})$, Citrus tangerine (47.84 $\pm 4.74 \mathrm{mg} / 100 \mathrm{gm})$ etc. (Deekshika et al., 2015).

So the wild edible fruits under investigation might be considered good sources of vitamin C. Therefore, the level of vitamin $\mathrm{C}$ in these wild edible fruits could be able to satisfy the recommended daily allowances (RDA) of 75 $\mathrm{mg} / \mathrm{day}$ and $90 \mathrm{mg} /$ day for adult women and men respectively, and $45 \mathrm{mg} /$ day for children of 9-12 years old.
Thiamine (B1), is an essential nutrient required by the body for maintaining cellular function and consequently a wide array of organ functions.

It is indispensable for energy production, carbohydrate metabolism and nerve cell function. The deficiency of this vitamin leads to deterioration of the nervous and circulatory systems, high blood pressure and cardiac aberrations resulting in amnesia (Akah and Onweluzo 2014; Akyilmaz et al., 2006).

Table.1 Retention time and parameters of calibration curve, precision and repeatability, LOD, LOQ and percent recovery study of standard water soluble vitamins for HPLC method validation

\begin{tabular}{|c|c|c|c|c|c|c|c|c|c|}
\hline $\begin{array}{l}\text { Name of the } \\
\text { Standard } \\
\text { Vitamin }\end{array}$ & $\begin{array}{l}\text { Detected at } \\
\text { wavelength } \\
\lambda \mathrm{nm}\end{array}$ & $\begin{array}{l}\text { Retention } \\
\text { time }\end{array}$ & $\begin{array}{l}\text { RSD (\%) } \\
\text { of the } \\
\text { retention } \\
\text { time }\end{array}$ & $\begin{array}{l}\text { RSD } \\
(\%) \text { of } \\
\text { the } \\
\text { peak } \\
\text { area at } \\
\text { conc } 40 \\
\mu \mathrm{g} / \mathrm{ml}\end{array}$ & $\begin{array}{l}\text { RSD } \\
(\%) \text { of } \\
\text { the } \\
\text { peak } \\
\text { area at } \\
\text { conc } 60 \\
\mu \mathrm{g} / \mathrm{ml}\end{array}$ & $\begin{array}{l}\text { Regression } \\
\text { Coefficient } \\
\mathbf{R}^{2}\end{array}$ & $\begin{array}{l}\text { LOD } \\
\mu \mathrm{g} / \mathrm{ml}\end{array}$ & $\begin{array}{l}\text { LOQ } \\
\mu \mathrm{g} / \mathrm{ml}\end{array}$ & $\begin{array}{l}\text { Percentage } \\
\text { of recovery } \\
(\%)\end{array}$ \\
\hline Vitamin C & 245 & 7.79 & 0.956 & 0.138 & 0.149 & 99.88 & 0.186 & 0.565 & 98.76 \\
\hline Vitamin B1 & 245 & 8.73 & 0.462 & 0.025 & 0.032 & 99.73 & 0.034 & 0.103 & 98.24 \\
\hline Vitamin B3 & 245 & 9.92 & 0.706 & 0.206 & 0.171 & 99.83 & 0.277 & 0.839 & 98.50 \\
\hline Vitamin B6 & 275 & 16.84 & 0.712 & 0.799 & 0.382 & 99.91 & 1.062 & 3.219 & 98.15 \\
\hline Vitamin B5 & 210 & 20.44 & 0.830 & 0.173 & 0.103 & 99.89 & 0.233 & 0.705 & 98.33 \\
\hline Vitamin B9 & 275 & 23.19 & 0.475 & 0.220 & 0.227 & 99.10 & 0.309 & 0.935 & 99.20 \\
\hline Vitamin B2 & 275 & 25.82 & 0.453 & 0.114 & 0.144 & 99.68 & 0.156 & 0.472 & 98.25 \\
\hline
\end{tabular}

Note: RSD: Relative standard deviation, LOD: Limit of detection, LOQ: Limit of quantification

Table.2 Quantification of Vitamin C and B1, B2, B3, B5, B6 and B9 in five wild edible fruits

\begin{tabular}{llllll}
\hline \multicolumn{5}{c}{ Vitamin content in $\mathbf{~ m g}$ / 100 gm dry plant material } \\
\hline Vitamin & M. indica & M. laxiflora & S. gilo & S. kurzii & V. foetidum \\
\hline Vitamin C & $13.43 \pm 0.04$ & $29.29 \pm 0.32$ & $51.59 \pm 0.40$ & $6.23 \pm 0.04$ & $12.18 \pm 0.06$ \\
Vitamin B1 & $0.092 \pm 0.003$ & $1.10 \pm 0.010$ & $0.87 \pm 0.007$ & $0.05 \pm 0.004$ & ND \\
Vitamin B2 & ND & $1.44 \pm 0.006$ & $0.72 \pm 0.02$ & $0.055 \pm 0.007$ & $0.25 \pm 0.007$ \\
Vitamin B3 & $4.43 \pm 0.03$ & $15.04 \pm 0.08$ & $0.43 \pm 0.008$ & $0.28 \pm 0.008$ & $0.13 \pm 0.003$ \\
Vitamin B5 & ND & $0.16 \pm 0.002$ & ND & ND & $0.16 \pm 0.004$ \\
Vitamin B6 & $0.17 \pm 0.002$ & $0.44 \pm 0.004$ & $0.64 \pm 0.01$ & $0.015 \pm 0.001$ & $0.30 \pm 0.006$ \\
Vitamin B9 & $0.045 \pm 0.001$ & $0.95 \pm 0.02$ & $0.10 \pm 0.004$ & $0.03 \pm 0.001$ & $0.51 \pm 0.004$ \\
\hline
\end{tabular}

Each value in the table was obtained by calculating the average of three experiments and data are presented as Mean \pm SEM. ND: Not Detected 
Fig.1 HPLC chromatogram of mixture of Standard vitamin

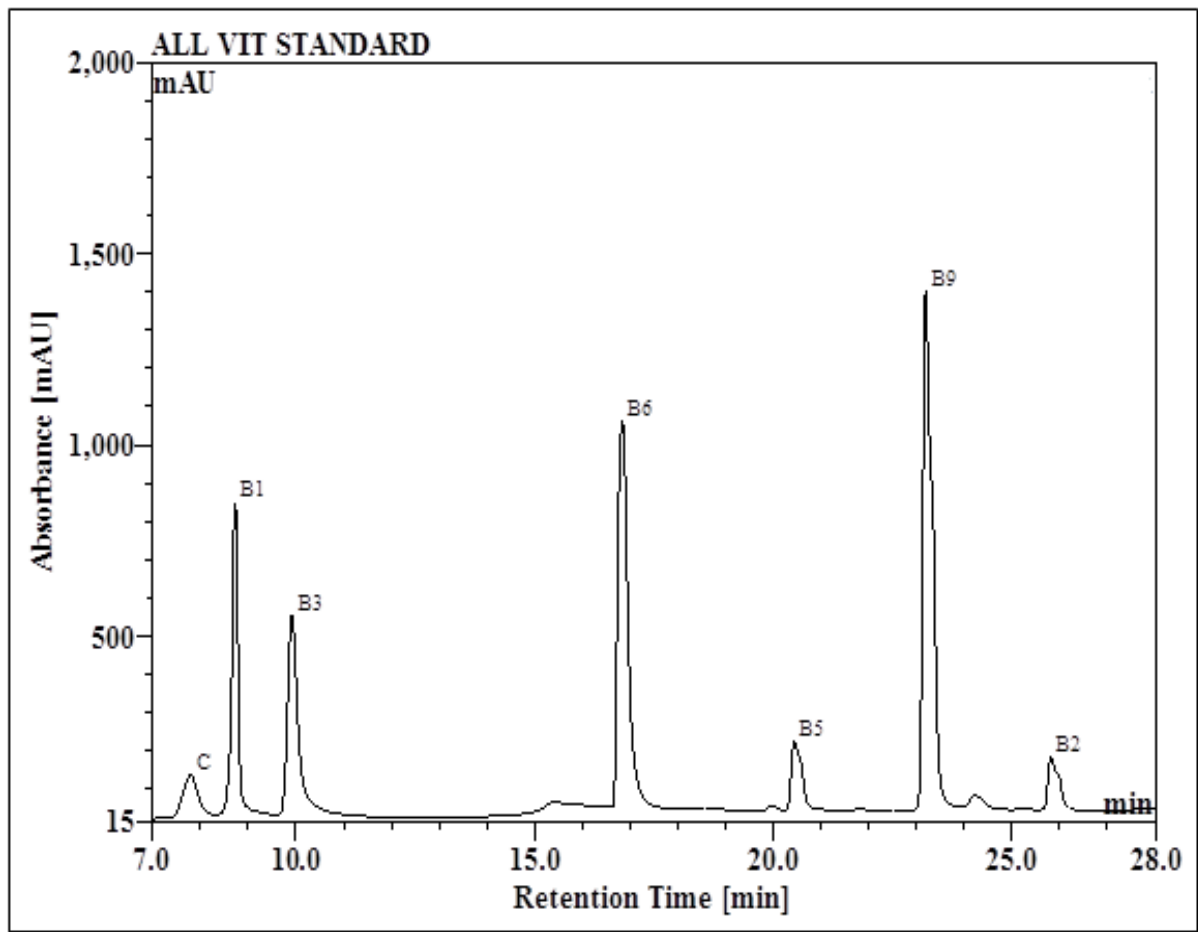

(C) Ascorbic acid; (B1) Thiamine; (B3) Niacin; (B6) Pyridoxine; (B5) Pantothenic acid; (B9) Folic acid; (B2) Riboflavin

Fig.2 HPLC Chromatogram of $M$. indica

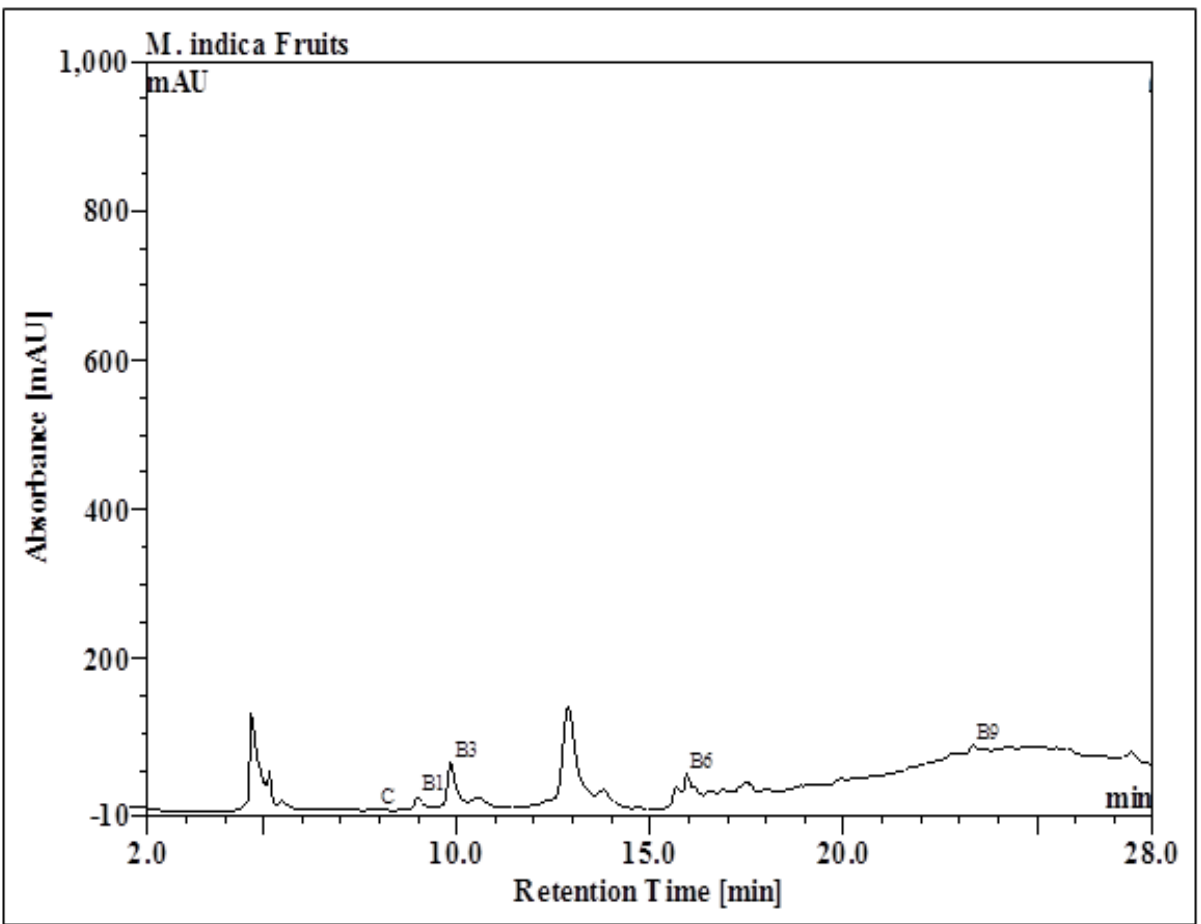

(C) Ascorbic acid; (B1) Thiamine; (B3) Niacin; (B6) Pyridoxine; (B5) Pantothenic acid; (B9) Folic acid 
Fig.3 HPLC Chromatogram of M. laxiflora

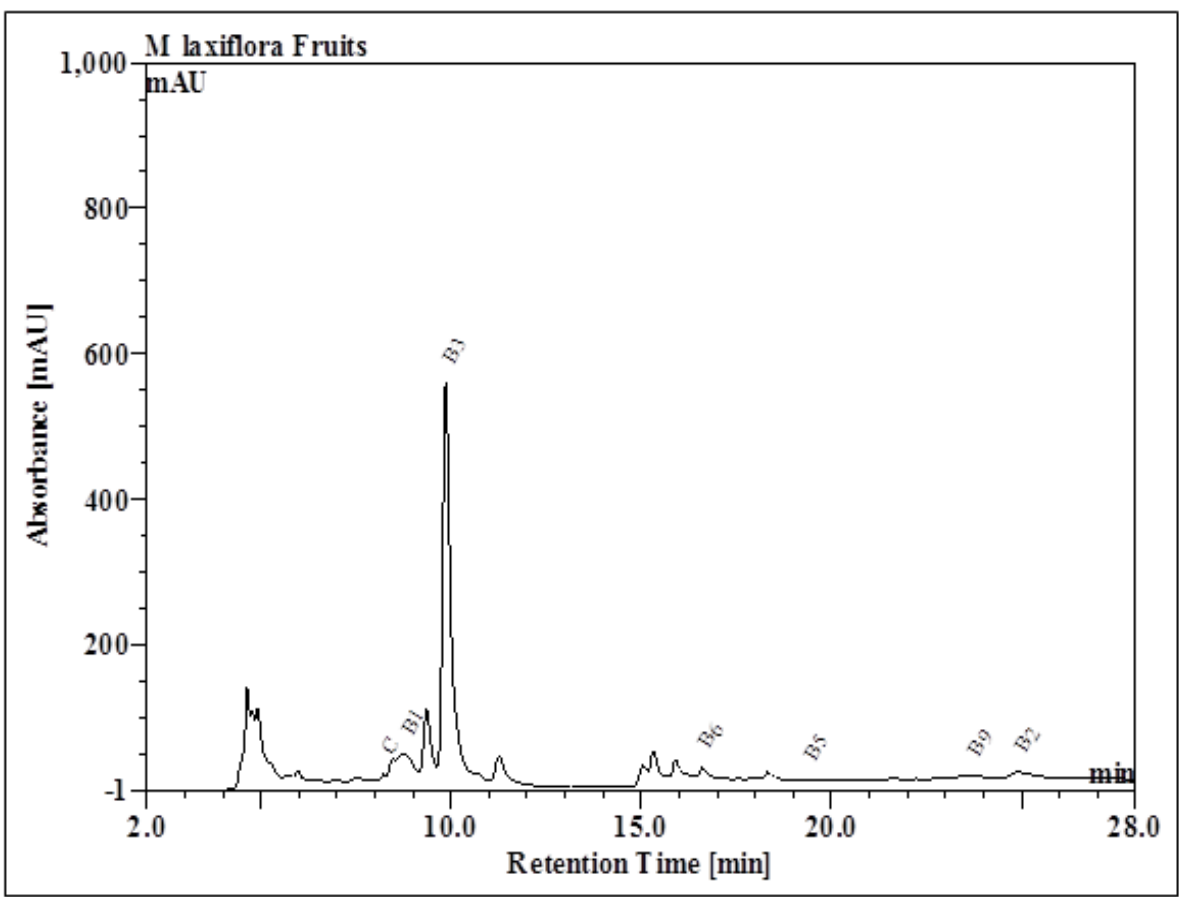

(C) Ascorbic acid; (B1) Thiamine; (B3) Niacin; (B6) Pyridoxine; (B5) Pantothenic acid; (B9) Folic acid; (B2) Riboflavin

Fig.4 HPLC Chromatogram of S. gilo

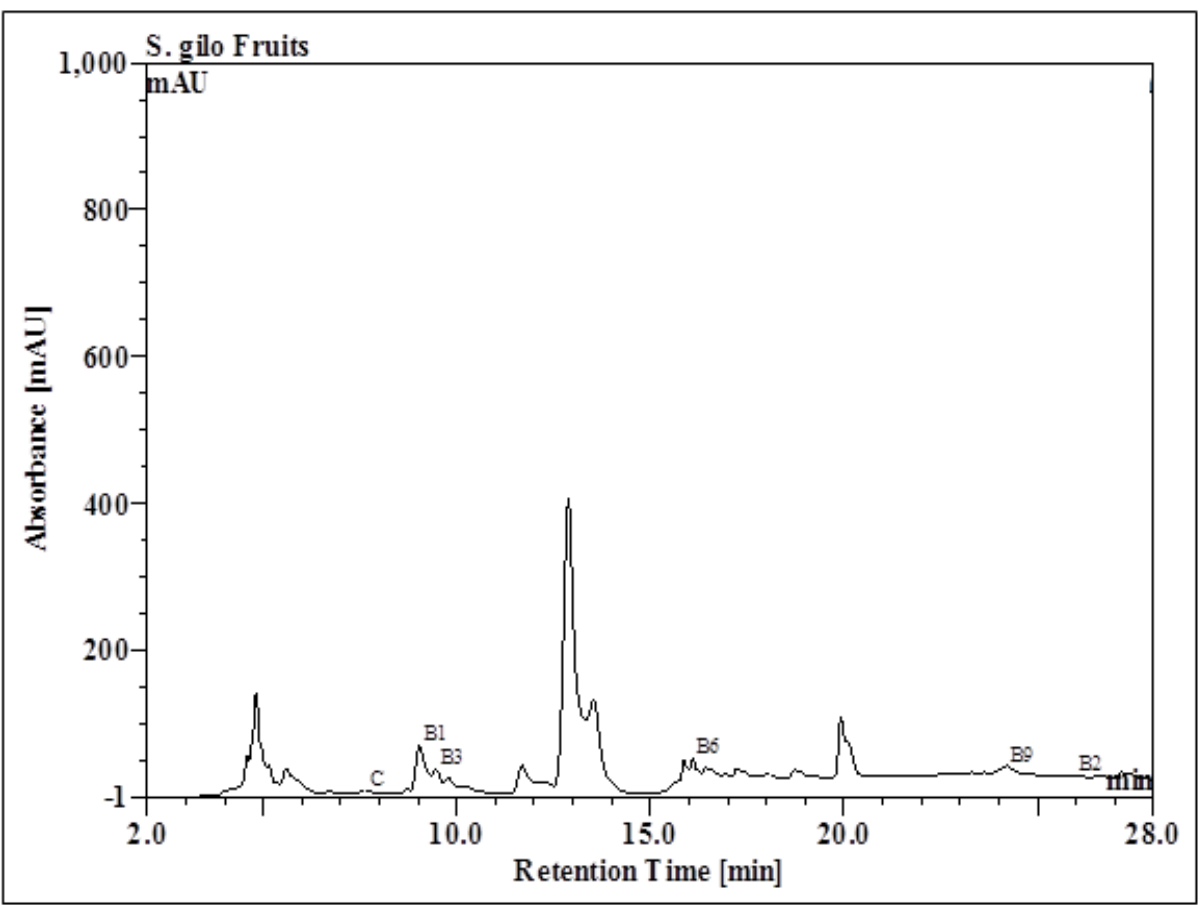

(C) Ascorbic acid; (B1) Thiamine; (B3) Niacin; (B6) Pyridoxine; (B5) Pantothenic acid; (B9) Folic acid; (B2) Riboflavin 
Fig.5 HPLC Chromatogram of S. kurzii

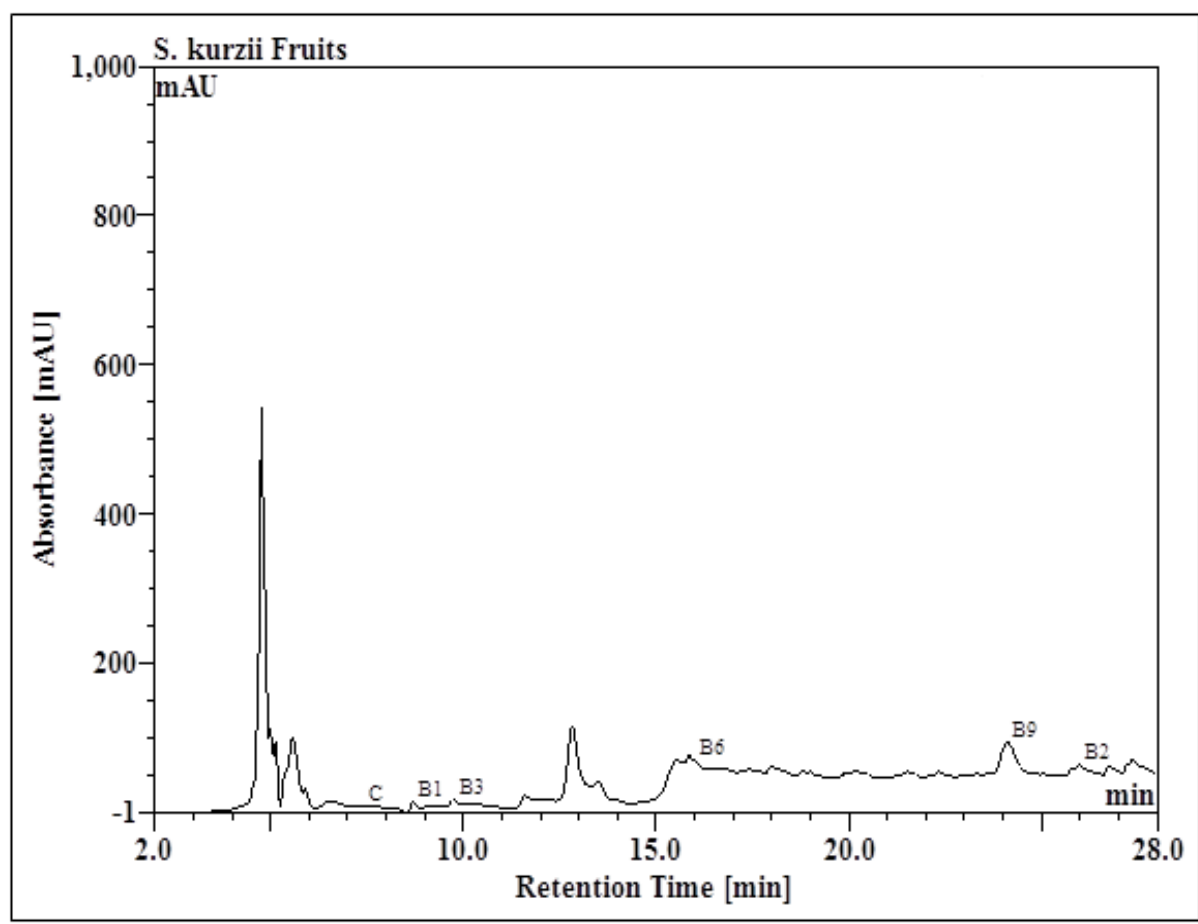

(C) Ascorbic acid; (B1) Thiamine; (B3) Niacin; (B6) Pyridoxine; (B5) Pantothenic acid; (B9) Folic acid; (B2) Riboflavin

Fig.6 HPLC Chromatogram of $V$. foetidum

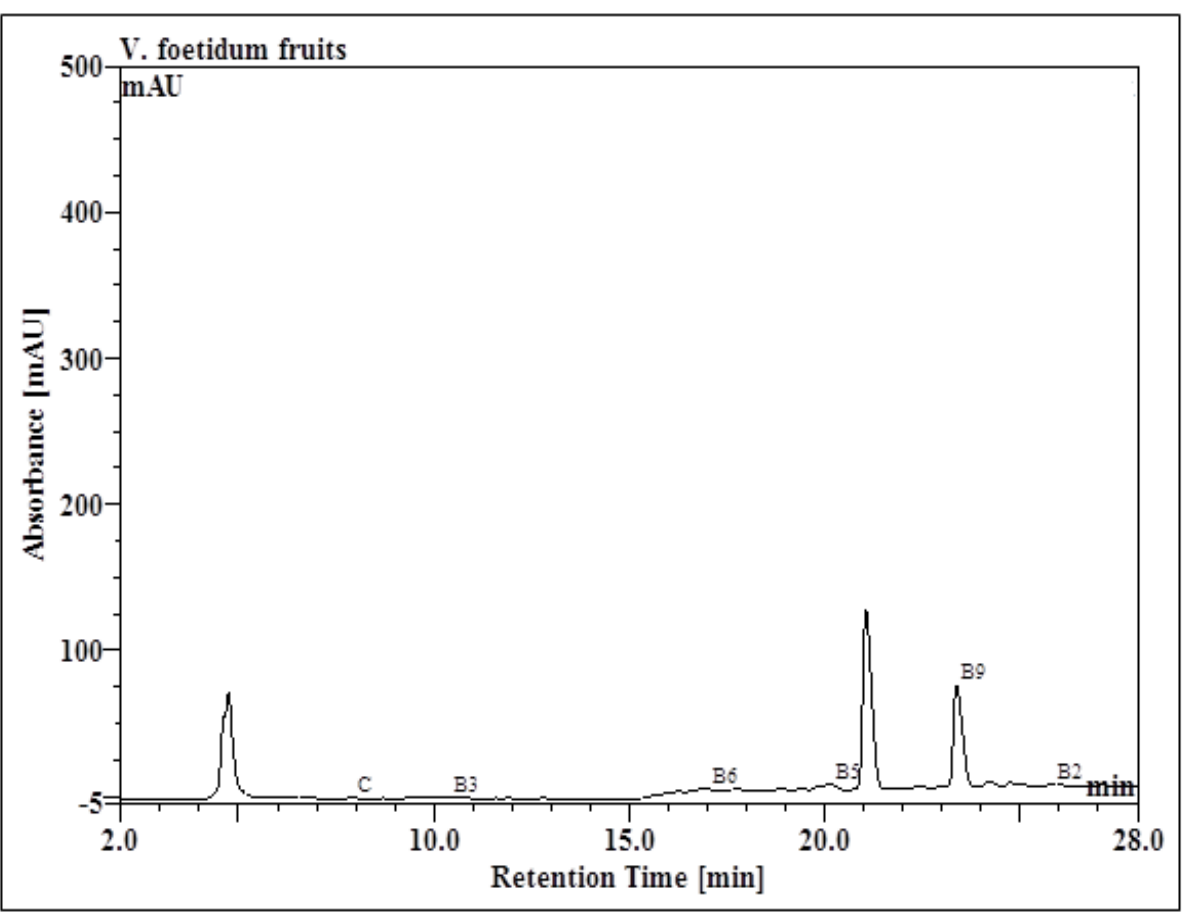

(C) Ascorbic acid; (B3) Niacin; (B6) Pyridoxine; (B5) Pantothenic acid; (B9) Folic acid; (B2) Riboflavin 
The thiamine content in these wild edible fruits ranged from $0.05 \pm 0.004$ to $1.10 \pm 0.010$ $\mathrm{mg} / 100 \mathrm{gm}$. The highest amount of B1 was obtained from the fruits of $M$. laxiflora followed by $S$. gilo and $M$. indica. This vitamin was not detected in the fruits of $V$. foetidum.

Thiamine has been shown to occur in some common vegetables and fruits like apple (0.016 mg/100gm), beans $(0.132 \mathrm{mg} / 100 \mathrm{gm})$, cauliflower $\quad(0.073 \mathrm{mg} / 100 \mathrm{gm})$, spinach $(0.076 \mathrm{mg} / 100 \mathrm{gm})$ etc and these amounts are very much similar to the thiamine content detected in the wild edible fruits under investigation.

Riboflavin (B2) plays an important role for metabolism and a wide variety of cellular processes and not associated with any specific deficiency symptom. It is the counterpart to thiamine used in the strengthening of food products (Boyaci et al., 2012). A significant variation of riboflavin content was noticed amongst the tested wild edible fruits. The highest amount of B2 was detected in the fruits of M. laxiflora $(1.44 \pm 0.006 \mathrm{mg} / 100 \mathrm{gm})$ and the least amount was detected in $S$. gilo $(0.72 \pm 0.02 \mathrm{mg} / 100 \mathrm{gm})$. The fruits of $S$. kurzii and $V$.foetidum were also found to contain a very good quantity of vitamin B2 which are comparable with some common fruits and vegetables like almonds $(1.10 \mathrm{mg} / 100 \mathrm{~g})$, spinach $(0.24 \mathrm{mg} / 100 \mathrm{~g})$, beet greens $(0.41$ $\mathrm{mg} / 100 \mathrm{~g})$, green beans $(0.12 \pm 2 \mathrm{mg} / 100 \mathrm{~g}$, potato $(0.023 \pm 1 \mathrm{mg} / 100 \mathrm{~g})$ etc.(Watada 1987).

The niacin (B3) content in the wild edible fruits under analysis ranged between $0.13 \pm 0.003 \mathrm{mg} / 100 \mathrm{gm}$ to $15.04 \pm 0.08$ $\mathrm{mg} / 100 \mathrm{gm}$. The highest amount of B3 was detected in M.laxiflora $(15.04 \pm 0.08 \mathrm{mg} / 100 \mathrm{gm})$ followed by in the fruits of $M$. indica $(4.43 \pm 0.03 \mathrm{mg} / 100 \mathrm{gm})$. The RDA for vitamin B3 for normal healthy adult is $15 \mathrm{mg} /$ day. Therefore these fruits are the important sources of vitamin B3. The fruits of $S$. gilo, $S$. kurzii, and V.foetidum also found to have necessary amount of vitamin B3 which were comparable with the B3 content in cabbage, cauliflowers, cucumber, spinach, tomatoes ranged between $0.19-0.97$ mg/100gm (Akah and Onweluzo, 2014).

Vitamin B3, is plays an essential role for processing fat in the body, lowering cholesterol levels, and regulating blood sugar levels. It is important in DNA repair, $\mathrm{Ca}$ metabolism, intracellular respiration, and biosynthesis of fatty acid and steroids (Institute of Medicine 1998). So the regular consumption of these fruits would supply adequate B3 necessary to maintain healthy body functions.

Vitamin B5, or Pantothenic acid, is an essential vitamin required by the body for cellular processes and optimal maintenance of fat. The deficiency of vitamin B5 leads to irritability, fatigue, apathy, numbness, paresthesia, and muscle cramps in human being (Gregory 2011).

Pantothenic acid was detected in very good amount in the fruits of M. laxiflora and in $V$. foetidum $(0.16 \pm 0.004 \mathrm{mg} / 100 \mathrm{gm})$. The vitamin B5 was not noticed in the fruits of $M$. indica, S.gilo and in S.kurzii.

Pyridoxine (B6) is another water soluble vitamin necessary for the proper maintenance of red blood cell metabolism, the nervous system, the immune system, and many other bodily functions.It also plays a role in homocysteine synthetic and degradative reactions (Rivlin, 2007). This vitamin is found in most food products and also, due to its stability, is often used for fortifying food products (Russell, 2012).

Vitamin B6 was quantified in all the wild edible fruits under our investigation. The highest B6 was noticed in S. gilo $(0.64 \pm 0.01$ 
$\mathrm{mg} / 100 \mathrm{gm})$ whereas the minimum was detected in $S$. kurzii $(0.015 \pm 0.001$ $\mathrm{mg} / 100 \mathrm{gm})$. The vitamin B6 content ranged between $0.17 \pm 0.002$ to $0.44 \pm 0.004 \mathrm{mg} / 100 \mathrm{gm}$ in other three wild edible fruits under investigation. The amount of B6 obtained in these wild edible fruits were comparable with some common vegetable and fruits like banana $(0.37 \mathrm{mg} / 100 \mathrm{~g})$, avocados (0.29 $\mathrm{mg} / 100 \mathrm{~g})$, spinach $(0.24 \mathrm{mg} / 100 \mathrm{~g})$, broccoli (0.134 $\mathrm{mg} / 100 \mathrm{~g}), \quad$ cauliflower $(0.115 \mathrm{mg} / 100 \mathrm{~g})$, cucumber $(0.2 \mathrm{mg} / 100 \mathrm{~g})$ etc.So the systematic intake of these fruits would supply sufficient B6 necessary to maintain healthy body functions.

Vitamin B9 (folic acid) is a water-soluble B vitamin with many rich natural sources. It is required for numerous body functions including DNA synthesis and repair, cell division, and cell growth. The shortage of folate can lead to anemia in adults, and slower development in children (Groff et al., 1995; Iyer \& Tomar, 2009; McGuire 2006; Stover, 2010). It plays an important role as an antioxidant in vivo, both by preventing the adverse effect of reactive oxygen species (ROS), as well as by inhibiting lipid peroxidation (Merola et al., 2013).

The extent of $\mathrm{B} 9$ in five wild edible fruits ranged from $0.03 \pm 0.001$ to $0.95 \pm 0.02$ $\mathrm{mg} / 100 \mathrm{gm}$. The content of B9 was found highest in $M$. laxiflora $(5.36 \pm 0.03 \mathrm{mg} / 100 \mathrm{gm})$ followed by good amount was detected in the fruits of $V$. foetidum $(0.51 \pm 0.004 \mathrm{mg} / 100 \mathrm{gm})$.

The reversed-phase HPLC method with diode array detection was developed for the quantitative estimation of water soluble $B$ vitamins (B1, B2, B3, B5, B6 and B9) and vitamin $\mathrm{C}$ in five wild edible fruits like M.indica, M.laxiflora, S.gilo, S.kurzii and V.foetidum, collected from North-eastern region in India. The established HPLC assay showed a well separation of the compounds and also the developed method was linear, sensitive, accurate, meticulous and reproducible. Therefore, the method can be used for the simultaneous determination of water soluble $B$ vitamins and vitamin $C$ in different formulations with 'shorter run time' and 'high efficiency'. RP-HPLC results showed the plants contained several water soluble $\mathrm{B}$ and $\mathrm{C}$ vitamins in varying amounts. The result of analysis of vitamin content in the wild edible fruits under investigation will serve as a useful means to calculate dietary intake of $\mathrm{C}$ and $\mathrm{B}$ vitamins in the general population. These data will also be helpful in the preparation of a complete food composition table for nutritional survey and also for other research purposes.

\section{Acknowledgement}

Authors of this paper are highly grateful to Dr. P. Singh, Director, Botanical Survey of India, Kolkata, for providing all facilities. We are also thankful to Dr. R. Shanpru, Scientist, Botanical Survey of India, Shillong for identifying the plant specimens.

\section{References}

Akah, N.P., and J. C. Onweluzo. 2014. Evaluation of water-soluble vitamins and optimum cooking time of fresh edible portions of Elephant Grass (Pennisetum purpureum L. Schumach) Shoot. Nigerian Food Journal, 32: 12027.

Akyilmaz, E., I. Yasa and E. Dinçkaya. 2006. Whole cell immobilized amperometric biosensor based on Saccharomyces cerevisiae for selective determination of vitamin B1 (thiamine). Analytical Biochemistry, 354: 78-84.

Boyaci, B.B., J. Han, M. T. Masatcioglu, E. Yalcin, S. Celik, G. Ryu and H. Koksel. 2012. Effects of cold extrusion process on thiamine and riboflavin contents of 
fortified corn extrudates. Food Chemistry, 132:2165-2170.

Ciulua, M., S. Solinasa, I. Floris, A.Panzanellia, M. I. Pilo, P.C. Piua, N. Spanoa and G. Sannaa. 2011. RP-HPLC determination of water-soluble vitamins in honey, Talanta, 83: 924-929.

Deekshika, B., B.P. Lakshmi, H. Singuluri and M. K. Sukumaran. 2015. Estimation of ascorbic acid content in fruits \& vegetables from Hyderabad, India - A theoretical assessment of Vitamin $\mathrm{C}$ activity. International Journal of Current Microbiology and Applied Sciences, 4: 96-99.

Gregory S. Kelly, 2011. Pantothenic acid. Alternative Medicine Review, 16 (3): 263-274.

Groff, J. L., S.S. Gropper and S. M. Hunt. 1995. Advanced Nutrition and Human Metabolism. 2nd Edition. Minneapolis/St. Paul New York Los Angeles San Francisco: West Publishing Company.

Harris, D.C., 2003. Quantitative chemical analysis. $6^{\text {th }}$ edition published by W.H. Freeman and Company: New York.

Hasan, N., M. Akhtaruzzaman and Z. Sultan. 2013. Estimation of Vitamins BComplex (B2, B3, B5 and B6) of some leafy vegetables indigenous to Bangladesh by HPLC Method. Journal of Analytical Sciences, Methods and Instrumentation, 3: 24-29.

ICH-Q2A. 1995. Text on Validation of Analytical Procedures.

ICH-Q2B. 1996. Validation of Analytical Procedures: Methodology.

Institute of Medicine. 1998. Dietary Reference Intakes (DRI) for Thiamin, Riboflavin, Niacin, Vitamin B6, Folate, Vitamin B12, Pantothenic Acid, Biotin and Choline. Washington (DC): National Academies Press (US).

Iyer, R., and S. K. Tomar. 2009. Folate: a functional food constituent. Journal of
Food Science, 74:R114-R122.

McGuire, J. J., 2006. Folic acid, folates and cancer. In A. B. Awad\& P. G. Bradford (Eds.), Nutrition and Cancer Prevention, (DOI: 10.1201/9781420026399.ch8), Boca Raton, Forida, USA: CRC Press (Taylor $\&$ Francis Group, LLC).

Merola, N., F.J.G Alonso, G. Ros and M. J. P. Cáston. 2013. Antioxidant activity comparison between [6S]-5methyltetrahydrofolic acid calcium salt and the related racemate form. Food Chemistry, 136: 984-988.

Olson, R. E., 1999. Water soluble vitamins.In Principles of Pharmacology.Edited by P. L. Munson, R. A. Mueller \& G. R. Bresse. (Chapter 59). NewYork: Chapman and Hall.

Pengfei, J., X. Lufeng, L. Zheng, C. Ning, Z. Ding and H. Xin. 2012. Rapid determination of thiamine, riboflavin, niacinamide, pantothenic acid, pyridoxine, folic acid and ascorbic acid in vitamins with minerals tablets by high-performance liquid chromatography with diode array detector. Journal of Pharmaceutical and Biomedical Analysis, 70: 151- 157.

Rivlin, R. S., 2007. Vitamin deficiencies. In C. D. Berdanier, E. B. Feldman \& J. Dwyer (Eds.), Handbook of Nutrition and Food, (2nd edition, pp. 177-292). Boca Raton, Forida, USA: CRC Press (Taylor \& Francis Group, LLC).

Russell, L. F., 2012. Water soluble vitamins.In L. M. L. Nollet\& F. Toldrá (Eds.), Food Analysis by HPLC, (3rd edition, pp. 325-442). Boca Raton, Forida, USA: CRC Press.

Seal, T., 2011. Antioxidant activity of some wild edible fruits of Meghalaya State in India, Advances in Biological Research, 5(3): 155-160.

Seal, T., 2011. Determination of nutritive value, mineral contents and antioxidant 
activity of some wild edible plants from Meghalaya state, India.Asian Journal of Applied Sciences, 4(3): 238-246.

Seal, T., 2011. Nutritional composition of wild edible fruits in Meghalaya State of India and their ethno-botanical importance. Research Journal of Botany, 6: 58-67.

Seal, T., and K. Chaudhuri. 2016. Identification and quantification flavonoids in two wild edible plants, Viburnum foetidum and Perillaocimoides of North-Eastern region in India, using High performance liquid chromatography with diode array detection. Journal of Medicinal Plant Studies, 4(5): 79-85.

Seal, T., B. Pillai and K. Chaudhuri. 2016. Identification and quantification of phenolic acids by HPLC, in two wild edible plants viz. Solanum gilo and Solanum kurzii collected from NorthEastern region in India. Journal of Chemical, Biological and Physical Sciences, 6(4): 1108-1121.

Seal, T., B. Pillai and K. Chaudhuri. 2016. Identification and quantification of phenolic acids by HPLC, in three wild edible plants viz. Viburnum foetidum, Houttuynia cordata and Perilla ocimoides collected from North-Eastern region in India. International Journal of Current Pharmaceutical Review and Research, 7(5): 267-74.

Seal, T., K. Chaudhuri and B. Pillai. 2016. Identification and quantification flavonoids in three wild edible plants, Houttuyniacordata, Solanum gilo and Solanum kurzii of North-Eastern region in India, using High performance liquid chromatography with diode array detection. Journal of Chemical and Pharmaceutical Research, 8(8): 859867.

Stover, P. J., 2010. Folate biochemical pathways and their regulation. In L. B. Bailey (Ed.), Folate in Health and Disease, (2nd edition, pp. 49-74). Boca Raton, Forida, USA: CRC Press (Taylor $\&$ Francis Group, LLC).

Watada, A. E., 1987. Vitamins C, B19 and B2 contents of stored fruits and vegetables as determined by High Performance Liquid Chromatography. J. Amer. Soc. Hort. Sci., 112 (5): 794-79.

\section{How to cite this article:}

Tapan Seal and Kausik Chaudhuri. 2017. High Performance Liquid Chromatography Method for the Estimation of Water Soluble Vitamin in Five Wild Edible Fruits Consumed by the Tribal People of North-Eastern Region in India. Int.J.Curr.Microbiol.App.Sci. 6(10): 29002913. doi: https://doi.org/10.20546/ijcmas.2017.610.343 